the drug's distribution (see page 420). But it was a difficult decision based on imperfect data - not least a lack of clinical comparisons between Avandia and other diabetes drugs including Actos, which is in the same chemical class but does not seem to pose the same risk of heart attack.

Few experts believe that Avandia became a blockbuster because it was demonstrably better than more established diabetes drugs. In the absence of comparative studies, many experts suggest that the drug's success was driven by an aggressive advertising campaign by its maker, the London-based pharmaceutical giant GlaxoSmithKline, and by clinicians' desire to offer their patients something 'new'. In 2006, the year before its safety risks were made public, global sales of Avandia reached $£ 1.66$ billion (some US $\$ 3$ billion).

Research suggests that heavy reliance on newer, patent-protected drugs is partly responsible for driving up the cost of treating diabetes, which in the United States rose from $\$ 6.7$ billion in 2001 to $\$ 12.5$ billion in 2007.

That does not mean there should not be a place on the market for Avandia. Many clinicians - even those sceptical of the drug's widespread appeal - say that it is a worthwhile treatment option for patients who cannot tolerate the side effects of the older drugs.

But Avandia is a clear example of why early comparative-effectiveness studies are needed for drugs that treat conditions for which therapies are already available. It is a lesson worth remembering as the United States begins to carry out the $\$ 1.1$ billion in comparativeeffectiveness research mandated by the American Recovery and Reinvestment Act of 2009, and as officials ponder whether and how the data collected should inform decisions made under the nation's newly reformed health-care system.

The issue is a highly contentious one in the United States, as many politicians there equate 'comparative effectiveness' with health-care rationing. But without these comparisons, as the Avandia example demonstrates, clinicians have only intuition and their own limited experience to guide their prescriptions. And when safety issues do emerge, regulators are forced to make decisions based on incomplete data. The studies need to be done consistently and early in the approval process, before the damage is done.

\section{An act of distinction}

\section{Researchers and activists alike benefit from dialogue - and a clear line between legal and illegal acts.}

W hen prosecutors in California charged four animal-rights activists with violations of the 2008 federal Animal Enterprise Terrorism Act (AETA) last year, they were vague about the actions involved - which is why the indictment was dismissed on 12 July. The act criminalizes "a course of conduct involving threats, acts of vandalism, property damage, criminal trespass, harassment, or intimidation" if it places individuals who work with animals, or their families, in fear for their lives or safety. Federal judge Ronald Whyte of the Northern California district court in San Jose said that prosecutors had not explained what the activists had done to cross a line.

The prosecutors have the option to re-indict if they can be more explicit. But a lawyer for the activists suggests that the prosecutors' vagueness on that first round was intentional: the specific actions, when set down in an indictment, might look suspiciously like 'speech' protected by the first amendment to the US constitution.

According to police reports, that speech allegedly involved shouting epithets at researchers on university campuses throughout California's San Francisco Bay Area - "Vivisectors go to hell!" and "You're a murderer!" being among the milder examples - writing slogans on the pavements outside researcher's homes; wearing masks; and banging on doors.

Whatever one thinks about such behaviour, the US constitution does protect even offensive free speech. Lawyers, ethicists and the research community should look critically at the AETA. Does it make the line between protest and crime clearer or blurrier? Is it even necessary?

There is a case to be made that it is not. Animal-rights activists causing trouble for researchers at the University of California, Los Angeles, have been successfully dealt with using court injunctions and existing anti-stalking laws, for example.

But there are also arguments to be made in the AETA's favour. According to Colin Blakemore, a University of Oxford neuroscientist with extensive and sometimes painful experience of the issues, similar laws enacted in the United Kingdom have been instrumental in raising awareness among police and prosecutors about the activists' gruelling organized campaigns. And when enforcement against activists was tightened, the result was a general relaxation among researchers and a boom in communication and openness.

Whatever the merits of the AETA, having a clear distinction between legitimate and illegitimate tactics is in everyone's best interest. Activists who want to protest legally need to know what is allowed, and researchers who wish to engage with legitimate animal-rights activists need to be able to recognize who they are.

Not every researcher believes that such engagement is worth pursuing, arguing that the minds of hard-core activists are already firmly made up. But engaging in dialogue with more moderate animalrights groups - particularly young people who might otherwise, in the future, become further radicalized - can be mutually beneficial, demonstrating to everyone that the opposing side are not monsters.

At the University of California, Los Angeles, where cars have been set alight, homes flooded and razor blades sent in the post, the US branch of the animal-research defence group Pro-Test and the campus animal-rights club Bruins for Animals put together a panel on animal-research ethics in February. The event culminated in a joint statement condemning harassment and intimidation that had been directed at those who participated in the panel.

Such steps are to be applauded. When researchers and non-violent animal rights advocates air their differences by communicating with one another, the result can be more than just a feel-good exercise. If labs communicate, animal lovers can be convinced that not all research involving animals is torture. And if activists persuade rather than frighten, researchers can be motivated to rethink experimental design and reduce their reliance on animals. 